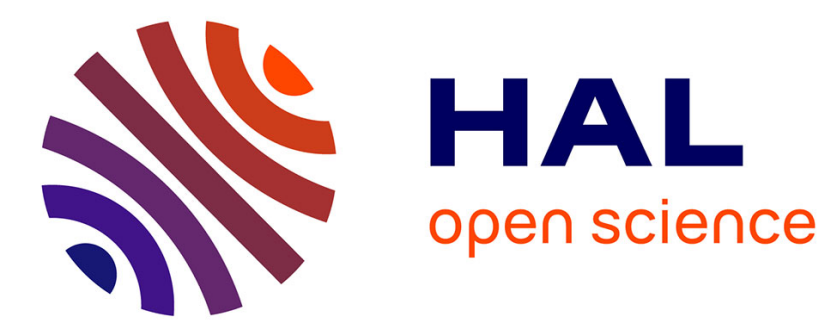

\title{
Production of metal matrix composites ingots from semisolid alloys
}

\author{
Ch. Vivès
}

\section{To cite this version:}

Ch. Vivès. Production of metal matrix composites ingots from semisolid alloys. Journal de Physique IV Proceedings, 1993, 03 (C7), pp.C7-1833-C7-1836. 10.1051/jp4:19937292 · jpa-00251935

\section{HAL Id: jpa-00251935 https://hal.science/jpa-00251935}

Submitted on 1 Jan 1993

HAL is a multi-disciplinary open access archive for the deposit and dissemination of scientific research documents, whether they are published or not. The documents may come from teaching and research institutions in France or abroad, or from public or private research centers.
L'archive ouverte pluridisciplinaire HAL, est destinée au dépôt et à la diffusion de documents scientifiques de niveau recherche, publiés ou non, émanant des établissements d'enseignement et de recherche français ou étrangers, des laboratoires publics ou privés. 


\title{
Production of metal matrix composites ingots from semisolid alloys
}

\author{
Ch. VIVÈS \\ Laboratoire de Magnétohydrodynamique, Université d'Avignon, 33 rue Louis Pasteur, 84000 Avignon, \\ France
}

\begin{abstract}
The working principle and the peculiarities of new electromagnetic rheocasters, which are based on the use of rotating permanent magnets and which allow the production of intense three-dimensional multiphase flows in solidifying semi-solid alloy slurries and metal matrix composites, are described. These processes are likely to be applied to the direct continuous casting of billets, tubes and slabs. They are also characterized by a very low electric power consumption. Local measurement techniques are applied to the study of the evolution of the fluid flow phenomena with the rotation speed of the inductor, the solid fraction, and the size and volume percent of SiC particles. A discussion is presented relating the metallurgical findings to the heat and fluid flow measurements. Satisfactory performances concerning the microstructure of solidified aluminum slurries and aluminum matrix composites (homogeneity, crystal shape, grain size, fraction of primary solid, distribution of SiC particles) were obtained.
\end{abstract}

\section{INTRODUCTION}

The techniques for fabricating metal matrix composites are very diversified and include compocasting, squeeze infiltration casting, high pressure infiltration casting and deposition technologies such as plating, chemical vapor deposition (CVD) and physical vapor deposition (PVD).

The compocasting method consists of the incorporation of third-phase particles of silicon carbide or alumina, for instance, within a vigorously stirred semisolid alloy slurry. This technique promotes good bonding between the reinforcement and the matrix and enables the achievement of a very homogeneous particle distribution. The working principles of the processes for preparing thixotropic alloy slurries are based either on mechanical or on electromagnetic agitation.

The mechanical stirring is commonly generated by means of augers, impellers or multipaddle agitators mounted on a central rotating shaft. However, the mechanical agitation approach is characterized by several specific and serious drawbacks. This process provides only a low volumetric rate of thixotropic slurry. There are technological problems related to the erosion of the rotor and it is not easy to associate mechanical agitation with a continuous casting system.

The employement of MHD casters constitutes an alternative rheocasting approach which is particularly attractive because the stirring intensity may be modulated at will, without any material contact between the rotating system and the melt and hence without risk of pollution of the metal. For example, in this process developed by WINTER, et al. I11, the metal is set in motion by a rotating magnetic field generated by a twopole multiphase motor stator and can be directly and continuously cast into either a vertical or a horizontal conventional mold. The aim of this investigation is to present an alternative approach based on the use of rotating permanent magnets which allow the production of intense stirring in solidifying alloys.

\section{EXPERIMENTAL APPARATUS}

The schematic sketch presented in Figure 1(a) relates to a first prototype which was used mainly for a fundamental study of the rheological behavior of semisolid alloy slurries performed by VIVES I2I. Figure 
1(a) shows the inductor, where the permanent magnets are arranged circumferentially around a cylindrical mold and alternately disposed according to a repetitive north-south azimuthal distribution. The rotor was driven, with an angular velocity wo, by an adjustable speed motor through a pulley-belt system permitting gradual variations of the speed of rotation N, ranging from 0 to 3000 r.p.m. When the inductor rotates, each point of the molten metal is subject to a variable magnetic field which generates induced electric currents. The main component of the current density is axial $\left(\mathrm{J}_{Z}\right)$ and the molten metal is set in rotation by azimuthal time-mean electromagnetic body forces, due to the interaction of the electric current $J_{Z}$ and of the radial component of the magnetic field $\mathrm{B}_{\mathrm{r}}$ (Fig. 1(a)).

The rotor consisted of four pairs of poles. Each pole, $24 \times 240 \mathrm{~mm}$ cross-section, was constituted by a row of ten parallelepipedic "ALNICO" permanent magnets of $30-\mathrm{mm}$ height and $24 \times 24 \mathrm{~mm}^{2}$ square crosssectional area. These magnets, magnetized along the greatest dimension, were embedded inside straight grooves machined along internal generatrices of a toroidal yoke made of stainless steel, with 130-and 165 $\mathrm{mm}$ inner and outer diameters, respectively.

In fact, in order to improve the homogeneity of the particle distribution in the alloy matrix, an helical rotor (Fig. 2) is preferable to a straight one. Figure 3 shows a part of a linearly developed rotor ; in the case of this sketch, where the sign of $\alpha$ and the direction of the synchronous speed of the rotating magnetic field are given, a downward vertical component of the time-mean electromagnetic body force $F_{Z}$ occurs in the vicinity of the mold wall. Depending on the direction of the inductor rotation the melt is subjected to upward (clockwise rotation) or downward (counterclockwise rotation) travelling magnetic fields. These travelling waves generate two circulation loops where the direction of the velocity near the wall coincides with the direction of propagation of the wave (Fig. 2). The combination of these recirculating cells with the main rotating vortex gives rise to strong helical flows. Consequently, the fluid motion is three-dimensional throughout and the reinforcement is prevented from agglomeration, floating or settling. Another repercussion is the effect on the free surface shape, which is modified under the action of both the electromagnetic pressure due to the vertical travelling wave and the dynamic pressure caused by the vertical velocity components. Accordingly, the free surface height can be significantly lowered ; this finding is of a primary importance because the entrapment of gas during the mixing process is significantly reduced.

The mold, made of stainless steel, consisted of an interior cylinder of 70-and 73-mm inner and outer diameters, respectively, and a coaxial external tube of 80 -and $84-\mathrm{mm}$ inner and outer diameters, respectively. An electric resistance, sunk in an insulating paste, was placed inside the annular gap formed between the two cylinders in order to control the cooling rate and to prevent untimely alloy freezing.

Various aluminum alloys were first melted using a direct-fired furnace and then poured into the molds. When a melt superheat on the order of $20^{\circ} \mathrm{C}$ was reached, particulates were incorporated at a permanent volumetric rate, while simultaneously, the electromagnetic stirring was started and maintained until the end of the slurry motion. Rheocast aluminum alloys billets of $70-\mathrm{mm}$ diameter and $240-\mathrm{mm}$ height were produced according to this procedure. Samples were taken by means of a small spoon, at various temperatures during freezing, and either solidified in air or rapidly quenched by immersion in water.

\section{THERMORHEOLOGICAL AND METALLOGRAPHIC STUDIES}

Experiments consisting in simultaneous recordings of velocity and temperature were carried out during the freezing of the solid-liquid mixture. To this end, a small thermocouple was fastened to an electromagnetic velocity probe. Figure 4 shows the evolution of the tangential velocity, measured at a given point, with the alloy solid fraction and for various percentages of $\mathrm{SiC}$ particles of 29 microns average diameter. Obviously, the velocity decreases when the $\mathrm{SiC}$ volume percent increases. Moreover, it is seen that the velocity decreases dramatically in the last stages of freezing.

A micrographical study has shown that the formation of a coarse rosette structure, which replaces a fine globular structure, is particularly favored in the final stages of solidification, when the shear rates are decidedly weakened. To achieve a homogeneous distribution of particles of small size in a metal-matrix composite material, the mean grain size of the globular crystals constituting the primary solid must be very small, in order to avoid the presence of large islands of particle-free matrix. Hence, it is advisable to cool the slurry rather rapidly, just before the onset of the decay of the flow rate. Accordingly, for the case of processes using MHD casters, the heat extraction rate appears as a key parameter in controlling the microstructure of the compocast materials. An example of distribution of SiC particles in a 2024 aluminum alloy matrix, obtained by this electromagnetic casting technique, is shown in figure 5 . 


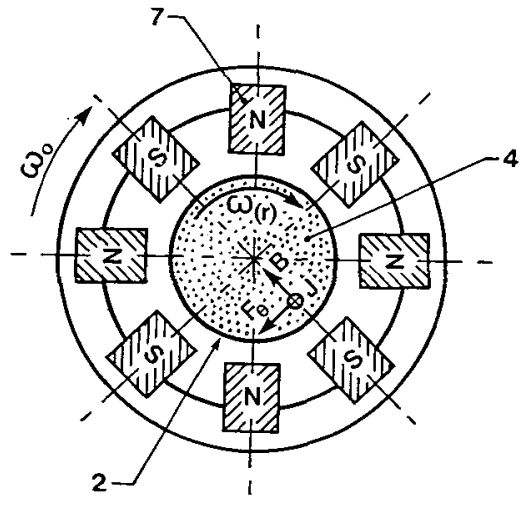

a)

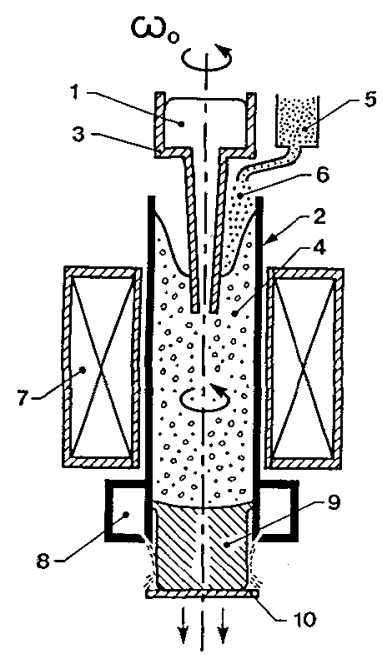

b)

Figure 1 : Schematic sketch of an electromagnetic compocaster equipped with an external rotor: (a) view from above and (b) front view - (1) molten alloy, (2) ingot mold, (3) spout, (4) multiphase mixture, (5) tank, (6) SiC particles, (7) rotor, (8) cooling water, (9) solidified alloy, (10) dummy bottom.

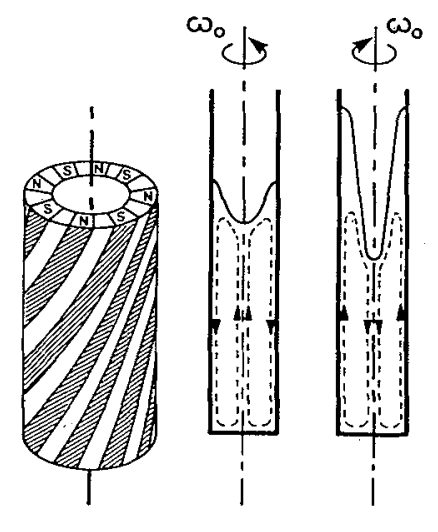

Figure 2 : Schematic sketch of an helical rotor and of the corresponding recirculating flows and free surface shapes.

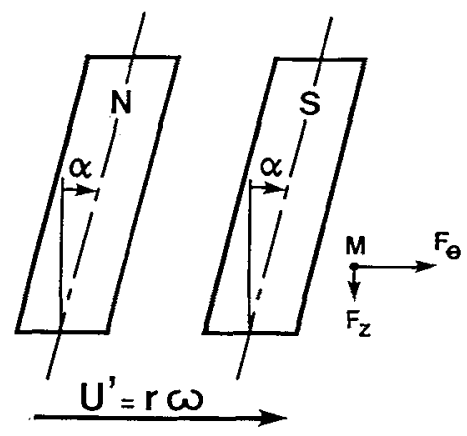

Figure 3 : Schematic sketch of the linearly developed rotor. 


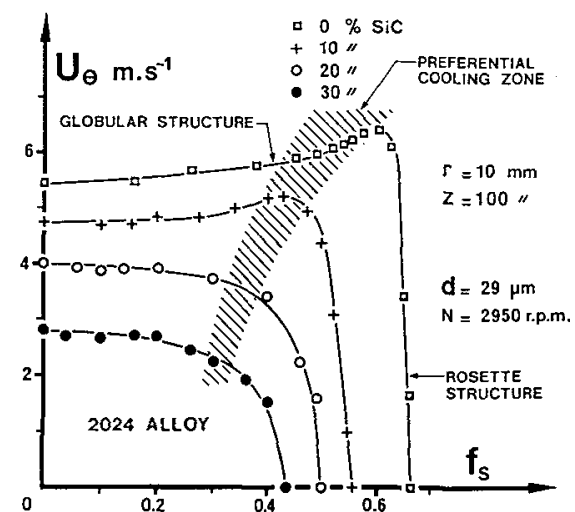

Figure 4 : Evolution of the local tangential velocity with the solid fraction, for a given rotational speed of the inductor and various percentages of $\mathrm{SiC}$ particles.

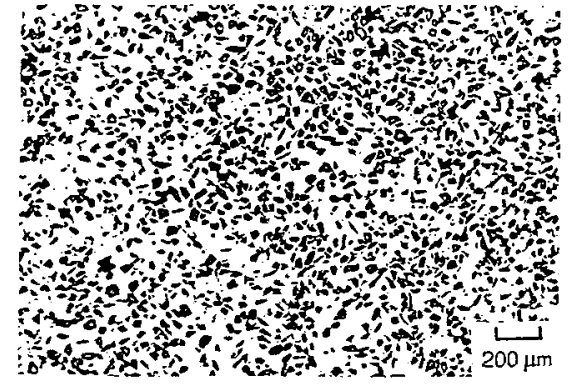

Figure 5 : Example of distribution of $\mathrm{SiC}$ particles (mean grain size $29 \mu$ ) in a 2024 aluminum alloy matrix.

\section{REFERENCES}

1 Winter, J., Dantzig, J. and Tyler, D., "Process and Apparatus for Making Thixotropic Slurries", U.S. Patent $\mathrm{n}^{\circ}, 469,486,1983$.

2 Vivès, Ch., "Elaboration of Semisolid Alloys by Means of New Electromagnetic Rheocasting Processes”, Metallurgical Transactions, Vol. 23 B, n 2, pp. 189-206, 1992. 